\title{
A NEW DESIGN OF ROCKWELL-BRINELL-VICKERS HARDNESS STANDARD MACHINE AT UME
}

\author{
C. $\mathrm{Kuzu}^{1}$, E. Pelit ${ }^{2}$, İ. Meral ${ }^{3}$ \\ ${ }^{1}$ UME, Kocaeli, Turkey, cihan.kuzu@ tubitak.gov.tr \\ ${ }^{2}$ UME, Kocaeli, Turkey, ercan.pelit@tubitak.gov.tr \\ ${ }^{3}$ UME, Kocaeli, Turkey, ilker.meral@tubitak.gov.tr
}

\begin{abstract}
:
After successful implementation of two hardness standardizing machines at TSE (Turkish Standards Institution) in Rockwell and Brinell-Vickers hardness scales separately, it became unavoidable to combine them in one machine with a newer design and install it in Hardness Laboratory of UME (National Metrology Institute of Republic of Turkey) within the scope of an internally funded project. In this paper the new design of the Rockwell-BrinellVickers hardness standard machine with deadweight force application principle and a laser interferometer optic system as depth measurement unit for Rockwell Hardness scales designed by UME Hardness Laboratory is explained.
\end{abstract}

Keywords: Hardness, Rockwell, Brinell, Vickers, Hardness Standard Machine.

\section{INTRODUCTION}

The activity of realization and development of primary Rockwell Hardness standard machine working in the same manner was made at Istituto Nazionale di Ricerca Metrologica (INRIM, National Metrology Institute of Italy) in the 70 years. With the cooperation of INRIM and a company called LTF S.p.a. in Italy, they together provided such machines to themselves and some other NMIs. UME also had designed and installed its own primary Rockwell Hardness standard machine in UME Hardness Laboratory in 2009 in the same manner with some modifications and a new machine for TSE in 2016 with a better design and more modifications.

After successful implementation of two hardness standardizing machines at TSE and with the demand and the necessity of renewing UME Hardness Standard Machines in Rockwell, Brinell and Vickers hardness scales, it became an important and unavoidable issue to combine them in one machine with a newer design and install it in Hardness Laboratory of UME within the scope of an internally funded project. In this project it is aimed at making use of the final design made for the TSE, overcoming the small defects of this design, improving some parts in terms of functioning, metrological properties and usage, and covering the missing hardness scales such as HV3, HBW2.5/6.25 etc.

In this new design the force application system was considered to comprise mass stacks realizing force under the gravitational acceleration and a newly designed frame to transfer the realized force to the tip of the indenter, to be working in the most straight forward way of deadweight force application principle. This time the mass stacks are also mentioned to be redesigned to be handled easily, during mounting/demounting onto the machine, calibration, repair/replace etc. The mechanical parts are completely renewed, aiming at more stringent, stable and reproducible machine.

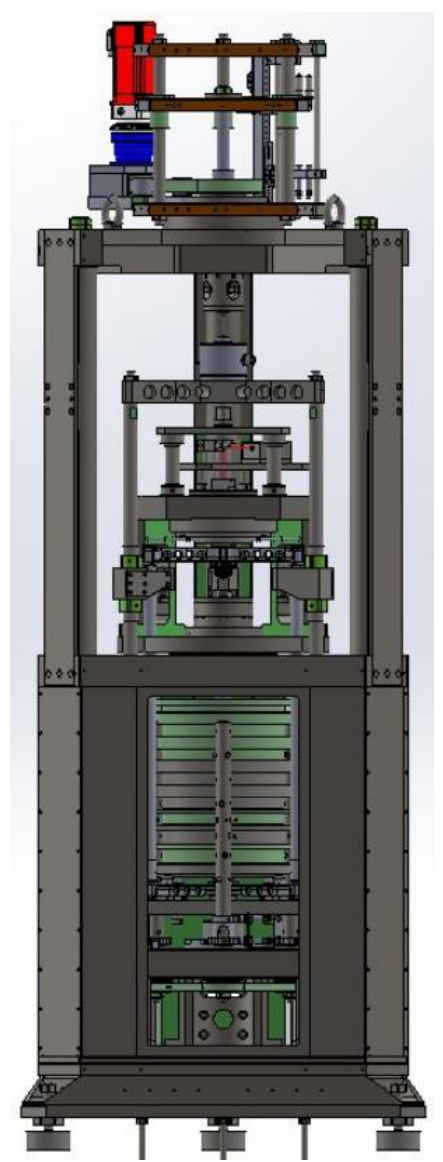

Figure 1: CAD of the Rockwell-Brinell-Vickers hardness standard machine 
A laser interferometer optic system is integrated to the machine as an indentation depth measurement unit. The depth measurement system is composed of laser source, linear interferometer and suitable optics mounted on top of the indenter, supposed to be in contact with the indenter and realize the same displacement as the indenter. In this way it will be easy to figure out the path through which the indenter is passing inside the material during realization of the hardness measurement.

The testing cycle is managed by making use of a load cell to which the whole force application system is mounted. The force application durations are sensed by measuring the force change on the load cell instantaneously during load application and comparing the measured force values with the nominal values belonging to the scale.

The indenter approach, force application and removal speeds will be adjusted and controlled by the laser interferometer system to control the servo motor (M1) which will be used for realization of the measurement cycle and force application rate is measured via the change in the load cell value in time. There is a second servo motor on the bottom side of the machine used to make automatic selection of the masses (scales) and with this design the machine will be completely automatic in terms of every step to realize the measurement cycle in Rockwell, Brinell and Vickers Hardness scales indicated in the table 1 and 2. The CAD of the machine is given in figure 1 and drawing in figure 2.
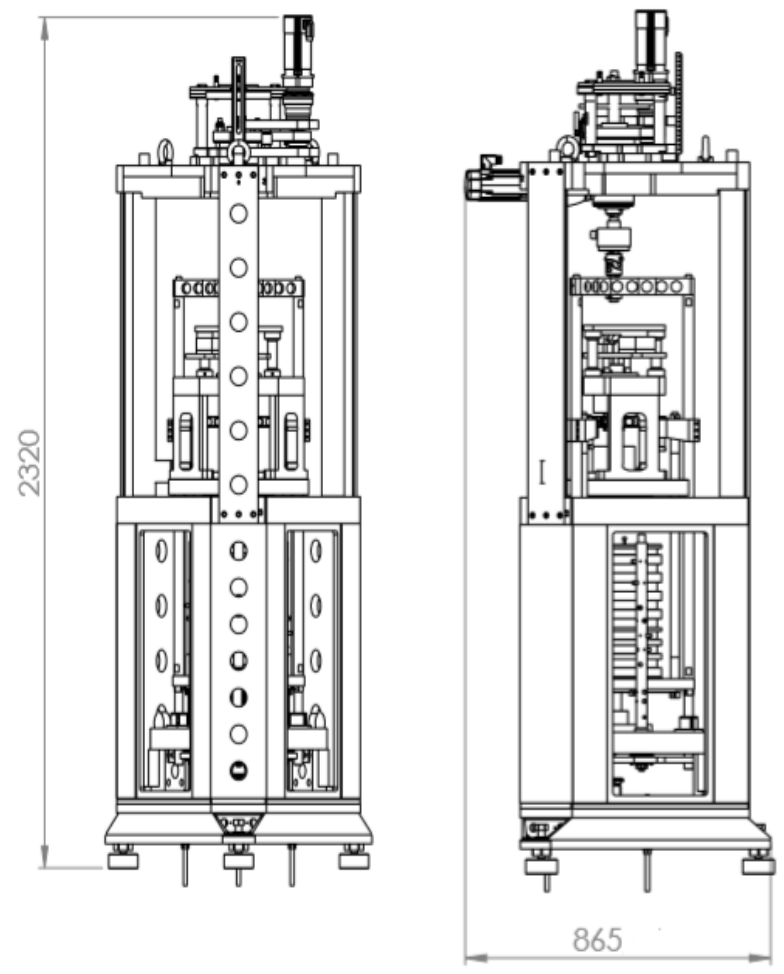

Figure 2: Rockwell-Brinell-Vickers hardness standard machine

\section{THEORY AND SCOPE}

The theory of Rockwell, Brinell and Vickers Hardness measurement, as well-known methods, are explained in detail in the relevant ISO Hardness Standards $[1,2,3]$. In all of the three scales the hardness measurement is mainly based on the realisation of indentation and measurement of the size of the indentation such as the depth, the diameter and the diagonal length, to be used for calculation of the Rockwell, Brinell and Vickers Hardness numbers, respectively, by making use of the empirical equation eqn. 1, eqn. 2 and eqn. 3 . These methods are completely used to measure mechanical property of material in line with the hardness definition, that is, the resistance which a material shows against deformation. In this paper the design of the machine used to realize the indentation with the highest accuracy and sensitivity in Brinell and Vickers scales and including depth of indentation in Rockwell scales is explained. Under these circumstances, regarding the theory, the following components are in the scope of this project:

$>$ force application with the highest accuracy

$>$ measurement cycle application precisely

$>$ indenter to realize the deformation

$>$ indentation depth measurement for Rockwell

A certain amount of force is applied on a defined shape and material of indenter through a predefined application cycle comprising force application speed and time durations where the force is kept on the indenter applied and shown in figure 3 .
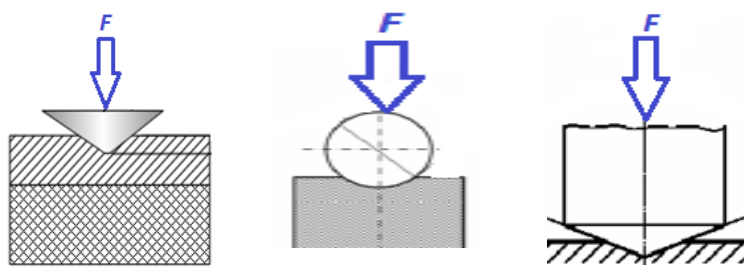

Figure 3: Realization of Rockwell, Brinell and Vickers hardness indentations (left to right)

After application of the measurement cycle, the realized indentation size, the depth is measured simultaneously; the diameter and the diagonal length are measured by some other device as shown in figure 4. Then the measured size of indentation is used to calculate the Rockwell, Brinell and Vickers Hardness values by making use of eqn. 1 [1], eqn. 2 [2] and eqn. 3 [3], respectively.
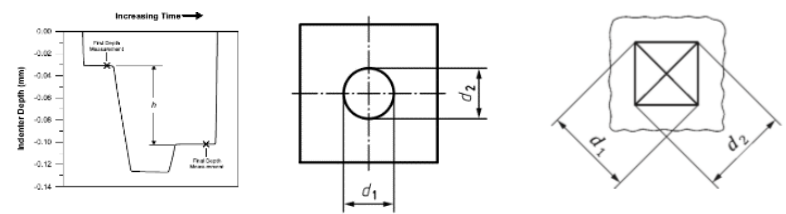

Figure 4: Measurement of Rockwell, Brinell and Vickers hardness indentation size 


$$
H R=N-\frac{h}{S}
$$

$$
H B W=0.102 \times \frac{2 F}{\pi D^{2}\left(1-\sqrt{1-\frac{d^{2}}{D^{2}}}\right)}
$$

$$
H V=0.1891 \times \frac{F}{d^{2}}
$$

Where,

$$
\begin{array}{lll}
H R & : \text { Rockwell Hardness } \\
H B W & : \text { Brinell Hardness } \\
H V & : \text { Vickers Hardness } \\
F & : \text { Force / N } \\
h & : \text { Indentation depth / } \mathrm{mm} \\
d & : \text { Indentation diameter/diagonal length / } \\
& \text { mm } \\
D & : \text { Ball diameter / } \mathrm{mm} \\
N, S & : \text { Constant }
\end{array}
$$

There are 15 Rockwell, 21 Brinell and 22 Vickers hardness scales defined by the ISO Hardness Standards, ISO 6508-1:2016 [1], ISO 6506-1:2014 [2] and ISO 6507-1:2018 [3] constituted with different combination of indenters and force values applied. All Rockwell Hardness Scales, some of the Brinell and some of the Vickers Hardness Scales are realized on this machine. The scales to be realized in Brinell and Vickers are highlighted in the table 1 and table 2.

Table 1: Brinell Hardness Scales to be realized

\begin{tabular}{|l|c|c|c|}
\hline Hardness symbol & $\begin{array}{c}\text { Ball diameter } \\
D \\
m m\end{array}$ & $\begin{array}{c}\text { Force-diameter index } \\
0,102 \times F / D^{2}\end{array}$ & $\begin{array}{c}\text { Test force value } \\
F \\
\text { N }\end{array}$ \\
\hline HBW 10/3 000 & 10 & 30 & 29420 \\
\hline HBW 10/1 500 & 10 & 15 & 14710 \\
\hline HBW 10/1 000 & 10 & 10 & 9807 \\
\hline HBW 10/500 & 10 & 5 & 4903 \\
\hline HBW 10/250 & 10 & 2,5 & 2452 \\
\hline HBW 10/100 & 10 & 1 & 980,7 \\
\hline HBW 5/750 & 5 & 30 & 7355 \\
\hline HBW 5/250 & 5 & 10 & 2452 \\
\hline HBW 5/125 & 5 & 5 & 1226 \\
\hline HBW 5/62,5 & 5 & 2,5 & 612,9 \\
\hline HBW 5/25 & 5 & 1 & 245,2 \\
\hline HBW 2,5/187,5 & 2,5 & 30 & 1839 \\
\hline HBW 2,5/62,5 & 2,5 & 10 & 612,9 \\
\hline HBW 2,5/31,25 & 2,5 & 5 & 306,5 \\
\hline HBW 2,5/15,625 & 2,5 & 2,5 & 153,2 \\
\hline HBW 2,5/6,25 & 2,5 & 1 & 61,29 \\
\hline HBW 1/30 & 1 & 30 & 294,2 \\
\hline HBW 1/10 & 1 & 10 & 98,07 \\
\hline HBW 1/5 & 1 & 5 & 49,03 \\
\hline HBW 1/2,5 & 1 & 2,5 & 9,807 \\
\hline HBW 1/1 & 1 & 1 & \\
\hline
\end{tabular}

Table 2: Vickers Hardness Scales to be realized

\begin{tabular}{|c|c|c|c|c|c|}
\hline \multicolumn{2}{|c|}{ Hardness test $^{\mathrm{a}}$} & \multicolumn{2}{c|}{ Low-force hardness test } & \multicolumn{2}{c|}{ Microhardness test } \\
\hline $\begin{array}{c}\text { Hardness } \\
\text { symbol }\end{array}$ & $\begin{array}{c}\text { Nominal value of } \\
\text { the test force, } F \\
\text { N }\end{array}$ & $\begin{array}{c}\text { Hardness } \\
\text { symbol }\end{array}$ & $\begin{array}{c}\text { Nominal value of } \\
\text { the test force, } F \\
\text { N }\end{array}$ & $\begin{array}{c}\text { Hardness } \\
\text { symbol }\end{array}$ & $\begin{array}{c}\text { Nominal value of } \\
\text { the test force, } F \\
\text { N }\end{array}$ \\
\hline- & - & - & - & HV 0,001 & 0,009807 \\
\hline- & - & - & - & HV 0,002 & 0,01961 \\
\hline- & - & - & - & HV 0,003 & 0,02942 \\
\hline- & - & - & - & HV 0,005 & 0.04903 \\
\hline HV5 & 49,03 & HV 0,2 & 1,961 & HV 0,01 & 0,09807 \\
\hline HV 10 & 98,07 & HV 0,3 & 2,942 & HV 0,015 & 0,1471 \\
\hline HV 20 & 196,1 & HV 0,5 & 4,903 & HV 0,02 & 0,1961 \\
\hline HV 30 & 294,2 & HV 1 & 9,807 & HV 0,025 & 0,2452 \\
\hline HV 50 & 490,3 & HV 2 & 19,61 & HV 0,05 & 0,4903 \\
\hline HV 100 & 980,7 & HV 3 & 29,42 & HV 0,1 & 0,9807 \\
\hline a Nominal test forces greater than 980,7 N may be applied. \\
\hline \multicolumn{7}{|c|}{} \\
\hline
\end{tabular}

\section{DESIGN OF THE MACHINE}

The machine body, every component constituting Rockwell, Brinell and Vickers Hardness scales, equipment used for measurements to control all parameters are considered to be with the highest accuracy to attain the most accurate outcome quantity hardness value. Beside the metrological properties, the functionality, easiness to use, stability and confidentiality are the main properties aimed at attaining and the design were made accordingly. Additionally production quality of the parts also play an important role in this design.

\subsection{Body of the Machine}

It is very important to have a rigid and sturdy enough body that will not affect the measurement results. For this reason, the machine body is designed to comprise the minimum number of parts with each having precise dimensional measurements and tight tolerances. All of the parts are produced with cast ironing with small dimensional tolerances at the places connecting to the other working parts. See the $\mathrm{CAD}$ of the machine body in figure 5 .

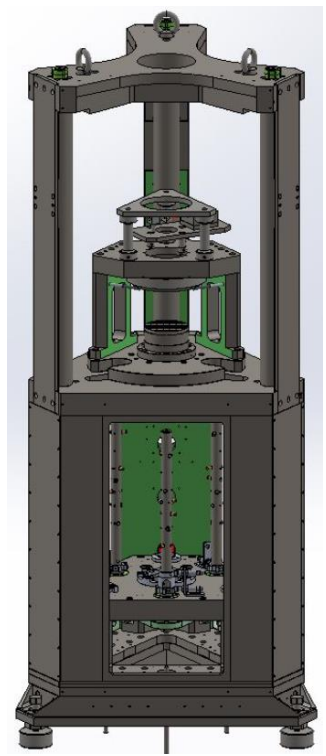

Figure 5: Rockwell-Brinell-Vickers hardness standard machine 


\subsection{Force Application System}

To realize the force with the highest accuracy and stability, deadweight type force application principle is preferred. It comprises mass stacks made up of stainless steel and a small frame to constitute the preload in Superficial Rockwell Hardness and HV3 in Vickers Hardness and transfer the other loads to the tip of the indenter. The frame is adjusted to apply $3 \mathrm{kgf}$ and the mass stacks will be in additional order to constitute the other force values and scales. The other mass stacks are $12 \mathrm{kgf}, 2 \times 15 \mathrm{kgf}, 8 \mathrm{kgf}, 40 \mathrm{kgf}$ (2x20) and $50 \mathrm{kgf}$ (in three pieces) to constitute the Rockwell scales and some Brinell and Vickers scales. To prevent this small frame from any pendulum and rotational motions during load application which will affect penetration performance of the indenter, it is guided by two air bearings at the two ends, both are working with (4-6) bar air pressure. The whole assembly of the masses and the frame are held by a high accurate force measurement sensor to control the testing cycle through measurement of the change in force in time and record the force application dwell time.

The masses are planned to be with high accuracy since they will be used in recalibration of the force sensor equipped onto the machine and may be used for calibration or intermediate check of the force measurement devices used in calibration/verification of hardness testing/calibration machines. The mass stacks are also guided while seating on each other. The six additional mass stacks and the small frame constituting the preload for Superficial Rockwell scales are shown in figure 6 .

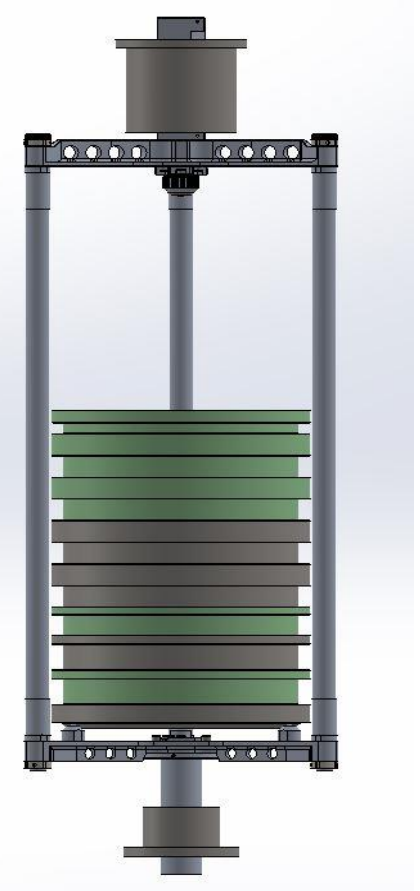

Figure 6: CAD of the force application system of Rockwell-Brinell-Vickers hardness standard machine

\subsection{Indentation Measurement System}

For indentation depth measurement, a laser interferometer optic system is equipped onto the machine. The linear interferometer is placed on an adjustable plate on the machine and a corner cube which is supposed to move as far as the indenter moves is placed onto the indenter and fastened to the indenter. By this manner, movement of the indenter is recorded by automation of the system and depth time graph is plotted. The target cycle expected to be measured is given in figure 7 .

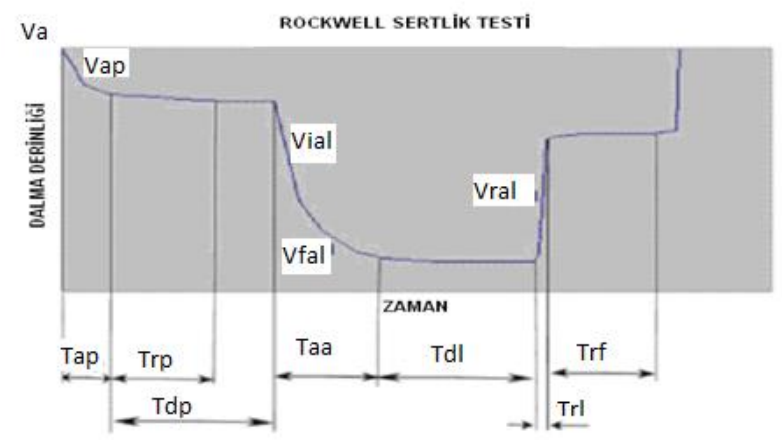

Figure 7: Expected depth of indentation measurement in Rockwell Hardness (defined by the CCM WGH)

\subsection{Measurement Cycle}

The measurement cycle is realized with application of force with a predefined indenter approach speeds and force application rates with respect to time. To figure out the measurement cycle of force application, a force measurement device is equipped onto the machine and data from this device is recorded and plotted as in figure 8 and 9. For indentation depth and speed of the indenter measurement in Rockwell Hardness scales a laser interferometer optic system is equipped on the machine. The speed of the indenter is measured by making use of the data taken from the laser interferometer. With the help of the speed information taken from the laser it is possible to characterize any test cycle for the material or sometime, depending on the hardness scale it is possible to realize a closed loop control. In this case the application speed is possible to correct and change to motor (M1) speed accordingly.
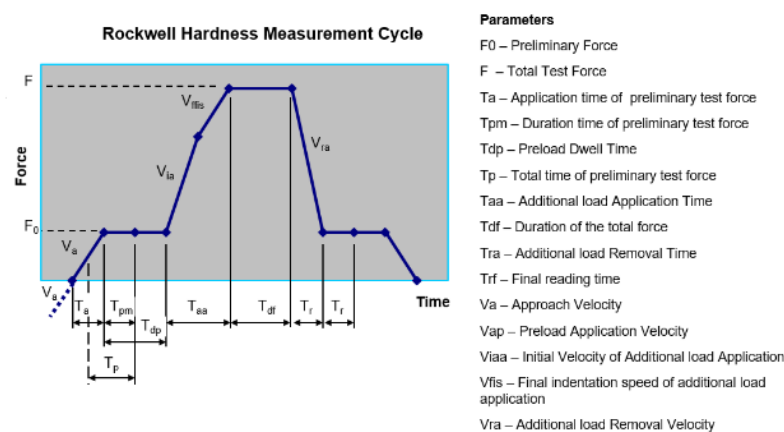

Figure 8: Rockwell hardness measurement cycle 

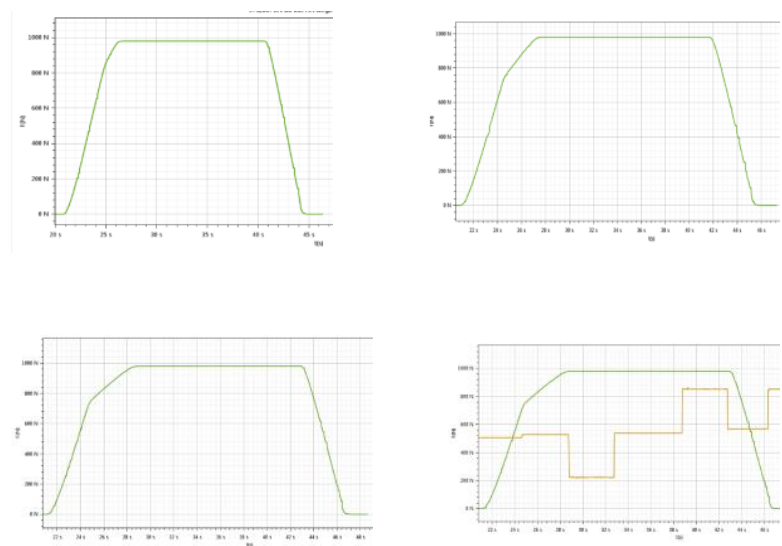

Figure 9: Brinell-Vickers hardness measurement cycle

\subsection{Automation of the machine}

The machine is equipped with two servomotor, one force measurement sensor and optionally one displacement measurement sensor as the main component of the automation. The main servomotor (M1) is realizing the indentation by moving the force application system up-and-down, the secondary servomotor (M2) is used to make the relevant mass stacks to realize the relevant scale, load cell besides the measurement cycle is used to sense loadingunloading, parking etc. There will be enough limit switches, ambient conditions measurement sensors and air pressure measurement gauge. We will try to perform closed loop control during load application to fix the load increase time in accordance with the load size and material properties like hardness.

\subsection{Performance of the machine}

In this paper the design of the machine is explained in detail, both in terms of mechanics and automation with hardware and software regarding the measurement cycle and measurement principle. The most important property of this machine is the accuracy and stability in force application method and the design of the system to realize precise and repeatable measurement cycle. As a full automatic dead weight force application system with laser interferometer, after the implementation of this machine the force uncertainty is expected to be less than $5.10^{-5}$ relative, that value may go down to $2.10^{-5}$ relative. The time uncertainty in measurement cycle is expected to be less than $0.25 \mathrm{~s}$. And the depth measurement uncertainty is expected to be $30 \mathrm{~nm}$ about. The uncertainties of the machine including its performance as a whole will be assessed and the results will be published accordingly after installation of the machine in UME Hardness Laboratory.

\section{SUMMARY}

At the end of the work explained above;

- A dead-weight type hardness standard machine is designed to realize Rockwell, Brinell and Vickers hardness scales in one machine.

- We have designed a new Rockwell-BrinellVickers Hardness Standard Machine in accordance with relevant ISO Hardness Standards [1], [2], [3], [4], [5], [6], with better metrological specifications.

- The scale selection, realization of measurement cycle and other functions are all possible automatically.

\section{ACKNOWLEDGEMENTS}

The author would like to thank Mr. Çetin DOĞAN, Mr. Murat KARABİNAOĞLU and Mr. Gökhan ÖNER from UME, the National Metrology Institute of Turkey, for their valuable contributions during the work has been done in this project of UME Hardness Laboratory.

\section{REFERENCES}

[1] EN ISO, 6508-1. Metallic Materials - Rockwell Hardness Test - Part1: Test Method, 2016.

[2] EN ISO, 6508-3. Metallic Materials - Rockwell Hardness Test - Part3: Calibration of Reference Blocks, 2015.

[3] EN ISO, 6506-1. Metallic Materials - Brinell Hardness Test - Part1: Test Method, 2014.

[4] EN ISO, 6506-3. Metallic Materials - Brinell Hardness Test - Part3: Calibration of Reference Blocks, 2014.

[5] EN ISO, 6507-1. Metallic Materials - Vickers Hardness Test - Part1: Test Method, 2018.

[6] EN ISO, 6507-3. Metallic Materials - Vickers Hardness Test - Part3: Calibration of Reference Blocks, 2018. 